\title{
Prostaglandins in human milk
}

\author{
A LUCAS AND M D MITCHELL \\ University Department of Paediatrics and Nuffield Department of Obstetrics and Gynaecology, \\ John Radcliffe Hospital, Oxford
}

SUMMARY Prostaglandins E and F have been shown to be present in breast milk in over 100 times the concentrations found in adult plasma. The ratio of the concentration of the principal circulating metabolite of prostaglandin $F(13,14$-dihydro-15-ketoprostaglandin $F)$ to prostaglandin $F$ itself is low $(0.3$ to 0.5 , compared with 15.8 in adult plasma), implying that prostaglandins may have a relatively long half-life in milk. In addition inactive metabolites of thromboxane $A_{2}^{\cdot}$ and prostacyclin are also found in significant amounts. It is speculated that milk prostaglandins play a role in modulating neonatal physiology-for example, gut motility.

Nutritive and antimicrobial aspects of human milk have received considerable attention. However, another, as yet unproved role for breast milk has emerged in recent years: milk may contain factors which modify or supplement physiological functions in the neonate. For example milk lipase ${ }^{1}$ may assist in neonatal fat digestion, and hormones in milk-such as thyroxine ${ }^{2}$-may have biologically significant effects. We have been interested in the possibility that milk prostaglandins consumed by the breast-fed infant might influence neonatal physiology-for example, gastrointestinal motility-yet there is very little information about these important lipids in human milk. We have therefore measured in milk, concentrations of prostaglandin E (PG E), prostaglandin F (PG F), together with 13, 14-dihydro-15ketoprostaglandin $F$ (PGFM), thromboxane $B_{2}$ $\left(\mathrm{TXB}_{2}\right)$, and 6 ketoprostaglandin $\mathrm{F}_{1} \propto$ (6 keto $\left.\mathrm{PGF}_{1} \alpha\right)$ which are inactive metabolites of PG F, thromboxane $A_{2}$, and prostacyclin respectively.

\section{Methods}

10 healthy lactating mothers, who had had spontaneous vaginal deliveries 5 to 7 days previously, consented to donate samples of foremilk and hindmilk which were manually expressed before and after a breast feed. These samples were immediately deep frozen and stored at $-20^{\circ} \mathrm{C}$ until assayed.

All prostanoids were measured by specific radioimmunoassays which have been described fully and validated elsewhere. ${ }^{3-5}$

Statistical analyses were performed using nonparametric tests: Mann-Whitney rank sum test for unpaired data, and Willcoxon signed ranks matched pairs test for paired data. However, for ease of comparison the data are expressed parametrically as means and standard errors.

\section{Results}

Breast milk concentrations of PG E were $149 \pm 37$ $\mathrm{pg} / \mathrm{ml}$ (mean \pm SEM) in foremilk and $224 \pm 63$ in hindmilk. Eight out of 10 paired samples showed a rise in concentration from foremilk to hindmilk $(P<0.02)$. These levels were very significantly higher than plasma concentrations of PG E of 1.3 $\pm 0 \cdot 1$ in healthy adults $(P<0.001)$ (Fig. 1).

PG F concentrations were similar in foremilk and

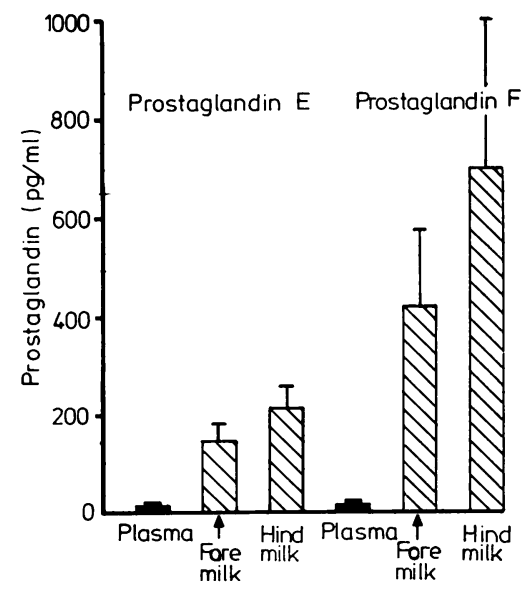

Fig. 1 Prostaglandin E and prostaglandin $F(\mathrm{pg} / \mathrm{ml} \pm$ SEM) in human milk and adult plasma. 
Table Prostanoid metabolites in human milk $(p g / m l \pm S E M)$

\begin{tabular}{lllc}
\hline & $\begin{array}{l}\text { Foremilk } \\
n=10\end{array}$ & $\begin{array}{l}\text { Hindmilk } \\
n=10\end{array}$ & $\begin{array}{l}\text { Plasma } \\
n=5-10^{*}\end{array}$ \\
\hline PGFM & $192 \pm 71$ & $214 \pm 86$ & $53 \pm 8$ \\
TXB & $283 \pm 132$ & $405 \pm 172$ & $103 \pm 18$ \\
6-Keto-PG F $F_{2 \alpha}$ & $222 \pm 57$ & $218 \pm 66$ & $115 \pm 24$ \\
\hline
\end{tabular}

*Values from papers by Mitchell3-5.

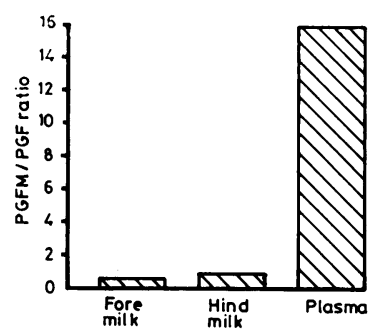

Fig. $2 P G F M / P G$ F ratio in human milk and adult plasma.

hindmilk $425 \pm 152$ and $671 \pm 322 \mathrm{pg} / \mathrm{ml}$ respectively and were greatly raised above the adult plasma level of $3.6 \pm 0.2(\mathrm{P}<0.001)$ (Fig. 1). PGFM concentrations were $192 \pm 71$ in foremilk and $214 \pm$ 86 in hindmilk, compared with $57 \pm 4$ in adult plasma $(\mathrm{P}<0.01)$ (Table). Thus, the mean PGFM/ PG F ratios were 0.5 for foremilk and 0.3 for hindmilk, both substantially lower than the mean ratio in adult plasma of $15 \cdot 8$ (Fig. 2). Foremilk concentrations of $\mathrm{TXB}_{2}$ and 6-keto-PG $\mathrm{F}_{1 \alpha}$ are shown in the Table and were similar to the maternal plasma values. $\mathbf{T X B}_{2}$ was significantly higher in foremilk than hindmilk $(P<0.02)$ but 6 -keto-PG $F_{1 \alpha}$ levels did not change during the feed.

\section{Discussion}

Prostaglandins are found in almost every tissue of the body and have a great variety of physiological roles. We have demonstrated that human milk contains large quantities of prostaglandins of the $\mathrm{E}$ and $F$ series (PG E and PG F), which were present in over 100 times the amounts found in adult control plasma.

These high concentrations might be explained simply on the basis of their lipid solubility, since human milk has a fat content of about $4 \mathrm{~g} / 100 \mathrm{ml}$ (40 $\mathrm{g} / \mathrm{l})$. Alternatively, it is possible that prostaglandins are secreted actively by the breast. The low PGFM:PG F ratio found in milk, compared with the ratio described previously in plasma, ${ }^{3}$ indicates that prostaglandins may not have been rapidly metabolised, a situation found in amniotic fluid. This raises the interesting possibility that these potent lipids could survive long enough in milk to exert an effect on the neonate.

It is thought that prostaglandins play a role in gastrointestinal motility. Both exogenous PG F, given to induce therapeutic abortion, and endogenous overproduction of PG E and PG F have been described in association with diarrhoea. ${ }^{6-7} \mathrm{We}$ have considered that ingested prostaglandins could also modulate gut motility. Pickles et al. ${ }^{8}$ thought that infantile diarrhoea might be due occasionally to excessive prostaglandin secretion into milk during menstruation, when maternal plasma levels of PG F may be raised, but it is possible that in the healthy breast-fed infant prostaglandins could assist peristalsis physiologically.

It is possible that differences in the pattern of bowel evacuation in breast-fed and bottle-fed infants could relate to differences in ingested prostaglandins. However, we have not studied prostaglandins in formula feeds, but PG F has been demonstrated to be present in substantial amounts in untreated cows' milk. ${ }^{9}$

It is interesting that in the case of PG E and the metabolite of thromboxane $A_{2}, T X_{2}$, the concentration rose towards the end of the feed. This cannot be explained entirely on the basis of the increasing milk fat content during a feed since the other prostaglandins measured did not behave in this way.

Two inactive metabolites, $\mathrm{TXB}_{2}$ and 6-ketoPG $F_{1 \alpha}$, were found in human milk at levels similar to those seen in control plasma. The presence of these lipids implies that milk contains, or contained, the parent compounds thromboxane $\mathrm{A}_{2}$ and prostacyclin. Thromboxane $A_{2}$ is a powerful vasoconstrictor and aggregates platelets whereas prostacyclin is a potent vasodilator and inhibits platelet aggregation. Since we were unable to measure these active forms directly, their survival in human milk is unknown and it is a matter for speculation if these biologically important lipids could exert a 'topical' effect on the gut, or perhaps be absorbed sufficiently to have systemic effects on the infant.

We thank Mrs J D Brunt for assay work and Professor A C Turnbull for advice and use of departmental facilities.

A $\mathrm{L}$ is in receipt of an ICIFI research fellowship, and $M$ D $M$ is a Medical Research Council senior fellow.

\section{References}

1 Hall B. Changing composition of human milk and early development of an appetite control. Lancet 1975; i: 779-81. 
2 Bode H H, Vanjonack W J, Crawford J D. Mitigation of cretinism by breast feeding (abstract). Pediatr Res 1977; 11 : 423.

3 Mitchell M D, Flint A P F, Bibby J, et al. Plasma concentrations of prostaglandins during human pregnancy: influence of normal and preterm labour. J Clin Endocrinol Metab 1978; 46: 947-51.

4 Mitchell M D, Bibby J, Hicks B R, Redman C W G, Anderson A B M, Turnbull A C. Thromboxane $\mathbf{B}_{2}$ and human parturition: concentrations in the plasma and production in vitro. $J$ Endocrinol 1978; 78: 435-41.

5 Mitchell M D. A sensitive radioimmunoassay for 6-ketoprostaglandin $F_{\alpha}$ : preliminary observations on circulating concentrations. Prostaglandins Med 1978; 1: 13-21.

- Dodge J A, Hamdi I, Walker S. Prostaglandin induced diarrhoea. Arch Dis Child 1977; 52: 800-2.
7 Rees W D W, Rhodes J. Letter: Altered bowel habit and menstruation Lancet 1976; ii: 475.

8 Pickles V R, Hall W J, Best F A, Smith G N. Prostaglandins in endometrium and menstrual fluid from normal and dymenorrhoeic subjects. $J$ Obstet Gynaecol $\mathrm{Br}$ Commonw 1965; 72: 185-92.

9 Hansell W, Hixon J, Shmesh M, Tobey D. Concentrations and activities of prostaglandins of the $F$ series in bovine tissue, blood, and milk. J Dairy Sci 1976; 59: 1353-65.

Correspondence to Dr A Lucas, Department of Paediatrics, Level 8, Addenbrooke's Hospital, Hills Road, Cambridge CB2 2QQ.

Received 26 November 1979 